\title{
Astrovirology, Astrobiology, Artificial Intelligence: Extra-Solar System Investigations
}

\author{
Paul Shapshak
}

\begin{abstract}
This chapter attempts to encompass and tackle a large problem in Astrovirology and Astrobiology. There is a huge anthropomorphic prejudice that although life is unlikely, the just-right Goldilocks terrestrial conditions mean that the just-right balance of minerals and basic small molecules inevitably result in life as we know it throughout our solar system, galaxy, and the rest of the universe. Moreover, when such conditions on planets such as ours may not be quite right for the origin of life, it is popularly opined that asteroids and comets magically produce life or at the very least, the important, if not crucial components of terrestrial life so that life then blooms, when their fragments cruise the solar system, stars, and galaxies, and plummet onto appropriately bedecked planets and moons.

It is no longer extraordinary to detect extraterrestrial solar systems. Moreover, since extra-solar system space exploration has commenced, this provides the problem of detecting life with enhanced achievability. Small organisms, which replicate outside of a living cell or host, would not be catalogued as viruses. How about viruses that cohabit with life? On the Earth, viruses are a major, if underestimated, condition of life - will that be the case elsewhere? Detection of extra-solar system viruses, if they exist, requires finding life, since viruses necessitate life to replicate. (It should be noted, though, that viruses could be detected through various types of portable ultra-microscopes, including Electron Microscopes (EM) (scanning and transmission) as well as Atomic Force Microscopes (AFM).) However, extra-solar system detection of life does not oblige that viruses exist ubiquitously. Viruses are important potential components of biospheres because of their multiple interactions and influence on evolution, although viruses are small and obligatory parasitic. In addition, nanotechnology - living or replicating nano-synthetic machine organisms might also be present out there, and require consideration as well. An imposing caveat is that, if found, could some extraterrestrial viruses and synthetic nanotechnological microorganisms infect humans?
\end{abstract}

This chapter is dedicated to Ettore Majorana, who changed the view of the universe.

\footnotetext{
P. Shapshak $(\bowtie)$

Division of Infectious Diseases and International Health, Department of Internal Medicine, University of South Florida, Morsani College of Medicine, Tampa, FL, USA

e-mail: pshapsha@usf.edu
} 
Possibly, intelligence and cognition may at times be contemporaneous with life. Concomitantly, life and viruses that may be detected, could well be impacted upon by intelligences existing on such exoplanets (and vice versa). Coming to an understanding of the plurality of extraterrestrial intelligence is an optimal objective, in order to avoid causing harm on exoplanets, as well as avoiding conflict and possible human devastation. This is especially the case if we encounter greatly advanced galactic-level civilizations, compared to terrestrial civilizations. Their machine and bionic technologies on the Dyson engineering civilization scale may be prominently superior to ours; their biological expertise may be similarly critically radical. For example, they may use viruses for purposes for which we are barely aware, and which could be utterly deadly for humans.

A series of steps is being taken in space exploration. Scientists hypothesize and claim that types of life may be near the Earth, in the solar system, and outside the solar system, similar to ours in the sense that only such conditions, Goldilocks conditions, are key sine qua non requirements, based on our terrestrial chemistry and biochemistry. If detected within the solar system, will life or its remnants resemble terrestrial life? Outside the solar system a similar chauvinism exists, although the likelihood for life, in any event, remains probably low, according to more cautious approaches to the problem. The study of our solar system includes planets, asteroids, comets, and other planetesimals that have been in overall contiguity during several billion years; anthropomorphisms claims life consequently has been developing along terrestrial-type mechanisms. However, a non-anthropomorphic view would surmise, probably not, especially for extra-solar system locales. The prime warning and admonition in all these deliberations is the contamination and damage, which current and past practice and procedures has caused and continues, due to insufficient biocontainment concepts and technology to date.

Advances in the development of robotics, artificial intelligence (AI), and high capacity ultrafast quantum computers (QC) greatly enhance the sophisticated control and logical development of extra-solar system studies. Consequently, future long-range manned space exploration seems unwarranted. Clearly, reduced dangers to human health and safety, will result from the use of intelligent machine-based investigations and besides, with increased cost-effectiveness. Space exploration comes at great cost to humanity as a whole and utilizes global resources. Consequently, appropriate organizational measures and planning/cooperation need to be in place. Moreover, the bottom line is that despite all the slogans and claims, there have been next to no financial benefits to our planet as a whole. Such financial and heedless difficulties need to be addressed, the sooner the better. In addition, prior to exposure to exoplanetary life, deep understanding of the problems of infectious diseases and immune dysfunction risks are needed. In addition, global efforts should avoid serendipity and stochasticity as this work should be directed with long-term organization, commitment, scientific, and technological methodology. This chapter briefly reviews such questions assuming a new paradigm for oversight of extrasolar system viral investigations including intelligence and life. Finances are included as an essential adjunct. 
Keywords Virus · Life · Intelligence · Cognition · Astrovirology · Astrobiology · Exobiology · Extreme environments and caves · Infectious disease · Isotope-effect - Isotope-radioisotope quantification and ratio - Chemical composition - Detection . Carbon · Nitrogen · Oxygen · Sulfur · Selenium · Silicon · Fractal · Thermodynamics $\cdot$ Entropy $\cdot$ Enthalpy $\cdot$ Sagan $\cdot$ Anaxagoras $\cdot$ Arrhenius · Schrodinger · Gibbs · Maxwell · Boltzmann · Fermi · Feynman · von Neumann · Majorana $\cdot$ Margulies $\cdot$ Extra-solar system life $\cdot$ Goldilocks $\cdot$ Through the looking glass paradigm $\cdot$ Enceladus $\cdot$ Europa $\cdot$ Mars $\cdot$ Contamination $\cdot$ Feed-back contamination · BSL-4 · Genetics · Inheritance · Biological hybrid · Propagatory system · DNA sequencing $\cdot$ Genome $\cdot$ Evolution $\cdot$ Robots $\cdot$ Nanotechnology $\cdot$ Atomic force microscopes (AFM) - Laser communications - Gravitational lens · General relativity · Neutrino · Artificial intelligence (AI) - Quantum computers (QC) $\cdot$ NASA $\cdot$ CDC $\cdot$ NIH

\section{Key Concepts}

Virus detection in extra-solar system locales depends on the presence of life. Intelligence detection in extra-solar system locales depends on the presence of life or on the presence of machines. Can these be detected? What is the extent of contamination with biological and junked material of the prior pristine extra-terrestrial environments in our Solar System? Have all the planets, asteroids, and planetesimals to which spacecraft were sent already damaged and contaminated the entire program of life detection in our solar system with biological, toxic, and junk contamination? In case terrestrial and extra-terrestrial biologies were similar, can biological hybrids form that are more pathogenic or toxic compared to either parental progenitor? Is this a danger even if they are dissimilar? Will this admonition endure with spacecraft having departed from our solar system? The highest level of biosafety biocontainment level (BSL-4) is used for the deadliest of known terrestrial viruses, such as Ebola virus. The severe problem of extraterrestrial contamination by terrestrial microbes and vice versa, the reverse possibility, requires careful and detailed examination, analysis, and technological improvement. Assessment of many constraints requires that intelligent machines sent to investigate life beyond the solar system, should have preeminent capabilities including Artificial Intelligence (AI), Quantum computers (QC), robotics, self-replication, and repair, nanotechnology, and von Neumann's "Universal Constructor". It is counter-productive to foster human exploration of life beyond the solar system, current human, financial, and technological conditions all considered. This chapter briefly provides synopses of diverse background and significant advances for virology/life detection elsewhere, within and beyond the solar system. ${ }^{1}$

\footnotetext{
${ }^{1}$ This includes viruses that can grow in microbes as well as in larger living systems.
} 


\section{Introduction}

The Goldilocks or through the looking glass paradigm assumes, usually that universally, all life embodies the same or similar terrestrial processes. This terrestrialcentric view of life is limited in scope. The complete chemistry of all the natural elements, metals and non-metals, is unknown, and the predictive abilities of quantum chemistry are thus far unable to solve such salient issues that face us, while extraterrestrial exploration continues.

Humans have been anthropomorphic, ethnocentric, and Earth-centric for millennia, as far back in time that we know of. This led to widespread provincial limited unscientific deficiencies to grasp intelligence and life in the universe. However, many ancient Greek and modern scientists and technologists opposed such views. As investigations commence of locales outside our terrestrial and solar system environments, we need to re-examine fundamental assumptions, hypotheses, and directions. Key concerns in such explorations include unnecessary human life endangerment, global wastefulness, improvidence, duplicative financial cost, and huge irresponsible toxic accumulation of terrestrial and space junk. This chapter contends that unrelenting development of AI, QC, and intelligent robotics for extraterrestrial exploration will remove human risk and endangerment from the equation, as well as reduce global costs.) [1-4]

\section{Extra-Terrestrial Life}

Could galactic-level civilizations exist that are greatly advanced? Is the Fermiparadox of detection still extant? Astronomers are inventorying the solar system including planets, planetoids, asteroids, comets, dust, particles, etc. Nonetheless, although objects circulate within the solar system, some arrive from extra-solar systems and interstellar space, can life be detected anywhere among these? If not detected directly, which objects may have putative signatures of life? [5-13].

\subsection{Opposing View - The Hidden Civilization Survival Hypothesis}

Wandel epitomizes the view that there is an inimitable abundance of life in the universe; this is based on threadbare evidence, if at all. The Drake equation is applied, the biosignature paradigm for the presence of life is applied, and the conclusion drawn. The assumption is, as usual, that Goldilocks planets are the harbingers of life, and percentages calculated to purportedly demonstrate the anticipation as to just how life must be so abundant [14]. 
This returns to a chapter theme that if there were any life elsewhere in the universe the problem of contact must be faced in regard to human health and safety based on virology, biology, and intelligence estimates therefrom. Moreover, there have already been proposals as to human measures of extraterrestrial intelligence base on feats of engineering accomplishments. Dyson proposed that sufficiently advanced civilizations could build spheres around their suns to provide greater energy capture needed for advanced technological progress - a stage of civilization technological development. Kardashev further proposed stages of development that proceed from the Dyson sphere capability, to the ability to move planets, and then finally to civilizations that could modify the structure of space-time itself to suit their needs. However, nothing of the sort has been detected as yet $[6,7,11,14]$.

The absence of life detection based on the Goldilocks paradigm could be the result of no existence of life in the first place out there, or it may be rarer than thought. In addition, intelligent life may survive some time prior to extinguishing itself. Possibly, intelligent life that does survive, may then rapidly hide itself. In this regard, several thousands of years of human history demonstrates the folly of displayed ostentatious resources readily discerned by others compared to less displayed wealth and existence.

Thucydides, in his history of the Peloponnesian war ${ }^{2}$ describes how Athens was able to initially grow and flourish, developing civilization and resources, because it was founded in an arid area that most other civilizations and cultures avoided [15]. Similarly, civilizations that hope to survive the unidentified dangers of the universe may know how to hide, strategically, from potential dangers and risks, and thus, to actually avoid Goldilocks zones.

\subsection{Life Cycles}

Various forms of life may have wide range cyclic durations, from transitory evanescence to long-term endurance. The time scales and examination methods used are critical and fundamental. Investigators could miss important clues as to the existence of such living systems, depending on the intervals, flexibility, and adaptability of how and when analyses were to be accomplished. A few demonstrative exemplars follow.

Possibly, investigators could miss cicada-like organisms that hide away for lengthy interludes. In Northeastern America, for example, distinctive cicada species have 13- and 17-year synchronous life-cycles. These two separate periodicities, generally, do not overlap, geographically. However, where there is geographical overlap, 221-year cycles occur [16, 17].

At the other end of the life cycle temporal spectrum, extra-solar system investigators could miss organisms that appear randomly (temporally and geographically),

${ }^{2}$ Peloponnesian War occurred 431-404 B.C. 
and very briefly. For example, species of mayfly adults live near fresh watersheds in England and have brief lifespans that vary from 5 minutes to 14 days. Their eggs are found in river beds and the next stage of development, nymphs, are found in proximity on river water plants. Subsequently, two separate additional adult stages develop on other riverside plants [18]. Consequently, if the investigators happened to look at night, or with inappropriate durations, or miss any of the precise locales, such explorers might not detect such mayflies. Moreover, even if they did detect various separate components of, as yet unknown (to them) life cycles, would they be able link the various mayfly developmental and maturational stages to then amalgamate the information into mayfly life cycles?

Undoubtedly, sequenced DNA genome phylogenies would divulge a lot; however, we cannot dubiously assume, per chance, that extra-solar system explorers will find living systems that utilize DNA. Some other types of genetics, inheritance, or propagatory systems may be used that have other means of genetics or 'memory' required as to how organisms reproduce or propagate. Panoplies of temporal range, location, and multiplicity of stages are thus important considerations investigators must address. Intelligent robotics, AI, and QCs are exceedingly applicable to conceive, plan, and address what needs to be constructed and assembled for successful and efficient extra-solar system investigations. Much work is currently being accomplished and the paradigm shift from utilization of humans to utilization of AI will accelerate the understanding and implementation of what needs to be done in preparation for such explorations. Additionally, large intelligent mechanical inventive systems necessitate development, which will implement obligatory changes upon arrival at extra-solar system target locales. Clearly AI will outperform humans and human intelligence $[19,20]$.

\subsection{Microfossils and Isotope-Radioisotope Quantification}

The detection of microfossils is important in confirming the early appearance of life on our planet and the use of isotope/radioisotope ratios is vital in enhanced dating methodologies [21, 22]. By the same token, in unmanned exploration of exoplanets, sophisticated apparatus using robots, AI, and QC are needed as well that can design and carry out measurement for isotope-radioisotope quantification in situ, in microfossils. This would have to be done across vast expanses of regolith, basalt, and sedimentary layers on such planets, carrying out in briefer times, what has taken more than a century of scientific and technological development and progress to accomplish, on our planet.

In addition, the conundrum of possible microfossils in foreign bodies that have plummeted onto planetary surfaces, fall into this domain. However, artefacts produced by severe heating when such objects fall through planetary atmospheres, and survive impact without complete annihilation, become questions of credibility and require additional support studies. Subsequently, how convincing is the claim for 
microfossils in such circumstances? Moreover, when falling onto planets or moons that are devoid of any atmospheres, such as the Moon, it is anticipated that such fossils will be more likely to survive under those conditions. To wit, if Martian microfossils have fallen to Earth, then as a control, should we not detect a plethora of such fossils on our Moon, which, after all, has weaker gravitation, negligible atmosphere, and a softer powdery regolith. An in depth analysis of the degree of flaw of claimed microfossil findings in terrestrial Martian rocks, is provided by Grady et al., who ask the question: "Martian meteorites are ancient microfossils. Do the data demand faith, hope, or charity?" Based on questions of chemical analysis techniques, generated artefacts in these fallen objects, and methods of evaluation, Grady et al. oppose the microfossil conclusion purported findings. It should be noted that as of January 2019, 224 of $61,000(0.4 \%)$ meteorites that fell to Earth were ejected from Mars [23, 24]. This does not support the occurrence of exobiology in our solar system.

\subsubsection{Viral and Particle Contamination - Biosafety}

Space exploration requires analysis of the conditions of physical and biological contamination including inanimate, such as dust, grains, and particles, and animate such as organisms of various sizes. Exploration of the Moon commenced some 50 years ago. In 1969, 1971, and 1972, six Apollo missions 11, 12, 14, 15, 16, and 17 landed on the moon and exhibited problems with lunar dust contamination of personnel clothing, space suits, and space vehicle cabins. Ubiquitous dangerous and deleterious effects of lunar dust were included in ten categories: inhalation and irritation, vision obscuration, false instrument readings, dust coating and contamination, astronaut space suit surfaces, loss of traction, thermal control problems, abrasion, clogging of mechanisms, and ball-bearing and seal failures. There were no effective procedures available to diminish the most serious problems of abrasion, clogging, and weakened heat rejection. The authors concluded that prior studies of these problems had been insufficient, so that additional studies will be needed prior to returning to the Moon and similarly prior to exploring Mars, if that is done. 21st Century ultra-sterile futuristic BSL-4 methods to prevent material and biological contamination should be used [25-29].

The complexity of detecting extra-solar system viruses and associated life is further heightened in consideration of incursion and clash with life that is potentially deleterious or hostile towards humans and their vehicles, AI, and other derivatives of our machines and technologies. Tribulations arising may be intentional or unintentional. Such warnings are exemplified using the following example of an unanticipated grim and dangerous lethal terrestrial virus, for which there is, as yet, no fully efficacious cure, Ebola.

This example is a huge international public health problem. Ebola epidemics are unanticipated, sporadic, and have high mortality. Based on phylogenetic studies, it appears that Ebola evolved in Africa for at least 1200 years, prior to its discovery. 
Ebola virus disease was discovered in 1976 in the Sudan and also occurred in the same year in Democratic Republic of the Congo (DRC). ${ }^{3}$ Ebola outbreaks and epidemics occurred in DRC in 1977, Sudan 1979, Philippines in 1989, Gabon 1994, Cote d'Ivoire in 1994, Gabon, 1995; DRC 1995, Gabon 1996 and 1997, Uganda 2000, Gabon 2001 and 2002, DRC 2001, 2002, and 2003, Sudan 2004, DRC 2005 and 2007, Uganda 2007, DRC 2008, Spain 2010, Uganda 2011 and 2012, DRC 2012, and a huge outbreak in West Africa (Liberia, Guinea) in 2013. Human Ebola virus infections were also detected in Lagos, Ghana, and Sierra Leone. Fruit bats are the reservoir for Ebola virus. Virus infected bats have been found in the DRC, Gabon, Lagos, Nigeria, and Ghana. Moreover, satellite telemetry is used to track bat migrations. Direct exposure to fruit bats can result in Ebola virus infection. In addition, Ebola virus has been identified in several animals including great apes such as chimpanzees. Ebola virus laboratory, clinical, and epidemiological studies are continuing due the devastating impact of this largely unanticipated disease [30-32].

At the start of the last few Ebola outbreaks and epidemics, however, international organizations, the NIH, and CDC were well prepared and promptly mustered the indispensable organizational, professional skill, complex technology, and rapid response required for the situations that unfolded. Biohazard suits were available for emergency teams and BSL-4 laboratories were already equipped and prepared to receive specimens for optical and electron microscopy as well as for various virologic, immunological, biochemical, and molecular analyses. Procedures for the proper transport of BSL-4-level specimens via commercial public airlines were in place and immediately utilized. In fact, there are 50 known BSL-4 laboratories world-wide, so the planet has a high degree of improved preparedness for various types of biological contamination problems. Indeed, the current 2019 Ebola epidemic in the Democratic Republic of the Congo is considered now at its worst and still spreading [29, 33-38].

National and international space programs should coordinate with US and International biological, microbiological, and virologic organizations, including $\mathrm{NIH}, \mathrm{CDC}$, and WHO. These Biomedical organizations are highly skilled expert and accomplished. They are well-rehearsed and prepared for preventing and dealing with viral including biological and material contamination and are expert in carefully controlled, statistical analysis of experimental-design limitations, as well as augmented predictive capabilities. Such cooperative planning will reduce unnecessary duplication and financial waste [39].

Such considerations, including the panoply and plethora of emerging virus infections in recent decades, cast great doubts on the dubious optimism shown by many astronomers and exobiologists that exoplanetary microorganisms are unlikely to cause damage to humans. This is counter to extensive evidence that viruses cross species barriers [40]. Moreover, whether microorganisms and viruses

\footnotetext{
${ }^{3}$ There was a Marburg virus outbreak in 1967 in Uganda; Marburg virus is a Filovirus related to Ebola virus.
} 
have arisen on Goldilocks ${ }^{4}$ or on non-Goldilocks exoplanetary environments, it is counter-productive and damaging to credibility, when avowed that the potential infectious pathogenicity and lethality of exoplanetary microorganisms and viruses, if they exist, are shrugged aside.

\subsubsection{Viruses Cross Species Barriers}

There is a plethora of viruses that have their origin in species other than where they are initially discovered. The following examples of such viruses, their original host, and original species jump-time are as follows: Measles virus (cattle and monkeys, since the origin of Homo sapiens), Smallpox virus (other primates and camels, more than 10,000 years ago), Influenza virus (water birds, pigs, horses, more than 5000 years ago), canine parvovirus (CPV) (cats and feline carnivores, since 1970's), HIV-1 and HIV-2 (old world primates, chimpanzees, early 20th century), SARS Corona virus (bats, since 1970's), Dengue virus (old world primates, less than 500 years ago), Nipah virus (fruit bats, continuously), Marburg and Ebola viruses (bats, continuously), Myxoma virus (rabbits, since 1950's), Hendra virus (fruit bats, continuously), and canine influenza virus (horses, 21st century) [41].

Remarkably, more recent studies among 19 virus families demonstrate that hostswitching is universal among the viruses studied including Hepadnaviridae, Polyomaviridae, Poxviridae, Papillomaviridae, Adenoviridae, Caliciviridae, Coronaviridae, Potyviridae, Herpesviridae, Paramyxoviridae, Parvoviridae, Togaviridae, Retroviridae, Flaviviridae, Bunyaviridae, Orthomyxoviridae, Reoviridae, Picornaviridae, and Rhaboviridae [42].

\subsection{Origin of Life}

Where and when were organic compounds first synthesized, how did they accumulate, and how were they disbursed? Possibly, there are multiple developmental phases resulting in the origin of life from abiotic biomolecular synthesis and organelle formation required for living systems. In addition, was there a slow or rapid process during which living systems arose and assembled? Be that as it may, the key issue raised is a contrast between the problem of how life arose on the Earth, vs. its arising on asteroids and comets, and in these cases infalling onto the Earth. Temperatures of ejection are important in understanding the temperatures rocks were exposed to prior to reaching Earth. For example, rocks on the Earth from Mars could have been exposed to ejection temperatures of $400{ }^{\circ} \mathrm{C}$. Additional studies

\footnotetext{
${ }^{4}$ Frequently, a paradigm, termed Goldilocks, or through the looking glass, is used that life found in the panoply of terrestrial environments is indicative of what should be anticipated for life in the rest of the solar system and universe.
} 
indicate a higher temperature when asteroids collide expelling chondrites. The ranges of temperature maximum of $1850-1900{ }^{\circ} \mathrm{K}$ and $17-20 \mathrm{GPa}$ for pressure peak were attained [43-46].

However, infall temperatures for rocks reaching the Earth could reach more than a thousand degrees K. For example, Jenniskens et al. found that cometary debris and asteroids that traverse the Earth's atmosphere are exposed to atmospheric temperature range of $2900-6000{ }^{\circ} \mathrm{K}$ (traveling at $19-61 \mathrm{~km} / \mathrm{sec}$ ) and $7600-14,000{ }^{\circ} \mathrm{K}$ (traveling at $71-85 \mathrm{~km} / \mathrm{sec}$ ). However, depending on whether such events occur in a predominantly $\mathrm{CO}_{2}$ or $\mathrm{O}_{2}$ atmosphere influences the results. As the ejecta are expelled from the infall rocks, they cool the further away they travel. Organic molecules could then be synthesized in a predominantly $\mathrm{CO}_{2}$ atmosphere compared to an $\mathrm{O}_{2}$ atmosphere where $\mathrm{C}$ would react to produce $\mathrm{CO}$ and $\mathrm{CO}_{2}$ [47].

\subsection{Early Sources of Organic Molecules}

Chyba and Sagan hypothesized [48] that the early Earth, prior to 3.5 Gyr ago, had several equivalent sources of organic molecules: impact shock-, UV radiation-, electrical discharge-propelled synthesis and infall from extraterrestrial objects. However, questions can be raised as to the actual quantification of each putative source, the accuracy of measurements, the degree of solar nebula opacity to UV radiation, influence and types of radioactivity, the strength and destructiveness of the solar wind during the course of these events, the reaction-rate and chemistry of isotope effects of deuterium in the aqueous environment, and the relative distributions of infall from chondrites, comets, and other solar system debris.

\subsection{Organic Compound Survival Under Extraterrestrial-Interplanetary Conditions: A Paradox}

Immanuel Kant, in the 18th century (in 1755), first proposed that the solar system condensed from gases and particles. In this theory, he relies on the concept of the atom derived from Lucretius in combination with the application of Newton's laws of gravitation, leading to processes of condensation [49]. The work of Immanuel Kant set the stage for subsequent inferences to be based on planetary evolutionary phenomena, leading to the origin of life.

The evolution of carbon-containing molecules is of subsequent relevance in terms of possibly detecting Goldilocks-zone hypothesized Earth-like life, as advanced in the 20th century. The analyses of the Murchison and many other carbonaceous chondrites have been typical study foci. However, the question as to the survival of organic prebiological compounds continues to be a prime question in 
studies related to the origin of life in the solar system, as well. For example, carbonaceous chondrites have been sources of amino acids, purines, and perhaps some pyrimidines. Do they reflect conditions related to the origin of life or synthesis during transit to the earth's surface? [50-53]. First, were compounds continually produced during the early history of the solar system (e.g. during the first Gyr) and then, second, various conditions would degrade and destroy these compounds (e.g. heat, impacts, radiation, radioactivity, ultraviolet light, cosmic rays, and solar wind.) Olivine basalt was returned from the lunar regolith to the Cornell University Space Center Planetary Laboratory (Ithaca, NY) and was pulverized and then mixed with amino acids. These mixtures were subjected to lunar surface proton irradiation, temperature, and high vacuum, and resulted in complete amino acid destruction, in entirety, in 5-cm mixture columns. The half-life of the amino acids was calculated at 4000 years [54].

Conditions would be different at various times and durations on asteroids, chondrites, proto-planetoids, planetesimals, Earth, other planets, satellites, and comets. Thus, one may ask the crucial question, did pre-biotic biochemistry occur and evolve on planets such as Earth, Mars, and Venus at various times in their histories or did this occur on a solar system-wide panorama, early in the solar system history. However, if it were solar system-wide, then did this occur in two phases for the Venus, Earth, and Mars? First as the planetary material precursors and compounds accreted, then when some planetary critical mass was attained resulting in volcanism and melting, consequent concomitant destruction of biological compounds ensued. Next, was it only after some level of cooling that there was in situ synthesis of protobiologicals on the Earth (and Venus and Mars) as well as raining down of such molecules, as described by Chyba and Sagan in1974 [48].

Is life then a product of individually rare events such as on planets alone, or as a result of solar system-wide events that contributed increased probabilities of biomolecular assembly and biogenesis. As time goes by, with additional well-controlled studies, this paradox should be resolved. Be that as it may, Loeb proposed that because at a redshift of 100-137, because the cosmic background temperature was 273-373 ${ }^{\circ} \mathrm{K}$, (thus, a widespread Goldilocks universe) organic molecules could have formed and perhaps life originated, though at that early stage of development of the expansion of the universe (only 10-17 million years of age) [55]. Using this slant, there could have been very early widespread origins of life over several million years, prior to the further cooling and evolution of the universe, towards what we observe today. This overall vantage is also proposed by Gibson [56].

\subsection{Terrestrial Ribosomes and the Origin of Life}

The thermodynamics involved in ribosome evolution and multiple linkages among proteins and nucleic acids may be involved in the energetics imposing evolutionary constraints in selection at the molecular intracellular level, especially during the epoch when the terrestrial atmosphere changed from a UV-penetrating atmosphere 
with no oxygen to one with little UV and an abundance of oxygen. ${ }^{5}$ The complexity of the origin of ribosomes involving proteins and RNA's may have taken place at an early stage of life, when RNA genetics predominated prior to the proliferation of DNA genetics, termed the RNA world [57-62].

Briefly, subsequent evolution of life including ribosomes and cell organelles, point to endosymbiont evolutionary processes. Eukaryotes (with mitochondria, plastids (chloroplasts), and mitotic apparatus) appeared due to the fusion of several separate endosymbiont prokaryote groups. Accordingly, note then, that at some stages of evolution, some prokaryote nucleated cells interacted with mitochondrial symbionts and others with both mitochondrial and plastid endosymbionts. The endosymbiont origin hypotheses were originated by Mereschkowsky in 1905 and championed by Margulis since 1967 [63-67].

Extra-solar system life searches utilize panels of sophisticated experiments available to establish the presence of many types of chemical reactions, pre- and postorigin of life, depending on the states of development, where exploratory vehicles land. Of under-rated importance, there should be improved biocontainment procedures in place to avoid upsetting and perturbing the evolution of life in such environments. As technology improves and further exploratory vehicles are sent, the danger of biocontamination becomes even greater. Each exploratory vehicle should have a probability value (p-value) attached - which should be lower than some crucial value that should be determined with appropriate scientific investigation. Many control experiments are required to fully investigate such potential contamination outcomes. The degrees of complexity involved additionally require $\mathrm{AI}$ and $\mathrm{QC}$ to accomplish such difficult and multifaceted tasks without destroying such environments. Such issues are obviously important in extra-terrestrial Goldilocks zone environments.

\subsection{Thermodynamics and Life}

Besides the many apparatuses and characteristics of life mentioned, it is also recognized that analysis of organization, symmetries, energetics, and thermodynamics are crucial components in the analysis of life. This way early recognized by Schrodinger. Life as we know, demonstrates several biochemical cycles including Nitrogen, Carbon, Oxygen, and Sulfur cycles as well as electron flow cycles in organelles including mitochondria and chloroplasts. For energy production, many electron-chain oxidation cycles are based on sulfur or oxygen. Molecular biosynthesis- and degradation-coupled cycles are additionally often cited including nitrogen fixation, urea cycle, glycolysis, Krebs cycle, and photosynthesis. Demonstrating extreme plasticity and adaptability, terrestrial life has infiltrated wide varieties of inhospitable extreme environments, nonetheless, of temperature, earth, atmosphere, and water (however, all considered in the Goldilocks zone) [68-74].

\footnotetext{
${ }^{5}$ Such considerations may be obviated for extra-terrestrial life, where other conditions may become imposed, in the event of the absence of UV and/or oxygen in the first place.
} 
Life demonstrates increased order and lowered entropy. The Gibbs equation is fundamental in such calculations.

$$
\Delta \mathbf{G}=\Delta \mathbf{H}-\mathbf{T} \Delta \mathbf{S}
$$

where $\mathrm{G}$ is Gibbs free energy, $\mathrm{H}$ is enthalpy, $\mathrm{T}$ is temperature, and $\mathrm{S}$ is entropy [75-77].

Since the external environment is an open system, it supplies energy for this to occur as well as an increase in disorder and increased entropy to offset life's demands on energetics. Indeed, according to some cosmologies, entropy is increasing in the universe (second law of thermodynamics) $[68,78,79]$. Thermodynamics and kinetics of chemistry in space exploration is productive as exemplified for Enceladus [80] An additional example of living thermodynamics is the GibbsDonnan equilibrium effect [81]. Technology needs to be developed to detect such thermodynamic effects due to the presence of life, prior to taking samples for analysis, thereby potentially harming and destroying what is under examination. The application of difficult and sophisticated methods including fractal, multifractal, and thermodynamic approaches would require some time to develop and optimize [82-89]. Anthropomorphism not intended, in terms of intelligence, scanning for the extraterrestrial equivalent of neurons (from an external vantage) is a daunting task. Robotics, AI, and QC would surely require development, in order to do such difficult and complex tasks.

Unanticipated and counter-intuitive properties of replication occur in terrestrial life, which are being comprehensively assessed, as indicated, for example, by studies of prions and prion-like proteins. On the one hand, prion proteins are produced from coding DNA exons; on the other hand, infectious prions can induce malformation of correctly folded proteins into misfolded neuropathological prions. This transformation is associated with a variety of human and animal diseases that have been carefully and scientifically studied since the early 20th century. Moreover, many proteins have prion-like sequences and may additionally participate in various disease processes. Unanticipated, amyloid fibril fatal associated involvement in Alzheimer's disease, may involve synergistic action with prions. Further relevant to Astrovirology, there is negligible immune response to prion disease itself (transmissible encephalopathies) in the natural setting. If anything, incipient immune reactions promote replication and spread of prion disease [28, 90-94]. Thus, exovirology portends unanticipated elevated health risks for human exploration, should life and viruses be discovered elsewhere.

Biomedical scientists recognize and widely discuss our incomplete understanding of the human genome. The salient feature of the incomplete information is that, remarkably, $98 \%$ of the human genome does not code for proteins. Therefore, the human genome is appropriately under close scrutiny using cutting edge contemporary molecular analytic technologies; these studies lead towards individualized medicine and are being done through extensive institutional organizational skills coupled with critical peer review [87, 88, 90, 95-102]. 


\subsection{Abiogenesis}

Abiogenesis may depend on how water interacts with other environmental variables. It should be noted, however, that although there is little evidence that such conditions intrinsically produce life (besides the single example of the Earth), such zones are certainly environments to where terrestrial life could relocate. As an additional example in the field, along such lines, using the anthropomorphic insular approach, a probability equation is postulated, to calculate probabilities for life on Earth [103].

However, an earlier Bayesian approach came to the conclusion that despite the existence of life on the Earth, it is an extremely unlikely event [104]. From this, it may be inferred that the focus on the Goldilocks zone in this restricted search for life may not be the most productive approach to take; detection may fail for many other life-forms.

The possibility of material exchange among planets is used to enhance the probability of abiogenesis [105]. There is a range of histories and types of planetary systems under which such exchanges could occur. Histories of migrating planets and their roving excreta further tone the clarification of planetary surface properties to be included in the framework of exploration of extra-solar systems [106-108].

\subsection{Extinction Events}

There have been five commonly acknowledged terrestrial extinctions of life to date on the Earth. Across the last 560 million years (MY), the mass extinction names and approximate dates are late-Ordovician, 440 MY ago; late-Devonian, 370-350 MY ago; endPermian, 250 MY ago; end-Triassic, 199 MY ago; and end-Cretaceous, 65 MY ago. How such cataclysmic events terminate life is under study. For loss of life, a 'trigger' mechanism is separated conceptually from a 'kill' mechanism. Trigger mechanisms are whatever events (e.g. asteroids) cause or initiate kill mechanisms. An interesting example, though subtle, is a kill mechanism proposed when atmospheric partial pressure $\mathrm{pCO}_{2}$ levels of $560 \mathrm{ppmv}$ are associated with an oceanic toxic $\mathrm{pH}$ of 7.9. This level can be reached both from below and from above [109].

Subsequent to each extinction event, the fundamental building blocks and biochemistry of life persisted, as some organisms survived and continued to evolve each time. A question posed is to what extent intelligent life evolved prior to or after each extinction event. However, the consensus appears to be that highest intelligence was attained after the fifth extinction, with the rise of mammals, primates, and humans. What about extinction events in our scientific exploration of extra-solar system life? Our explorations necessitate including methods to ascertain whether extinction events have taken place, if our arrival is in the midst of such an event, and whether our arrival itself may cause such events. Dealing with questions of contamination is crucial. The footprint impacts of our exploration and arrival elsewhere should be explored scientifically. 


\section{Goldilocks Zone - Through the Looking Glass}

Many biochemists and biologists have concluded that although several possible lineages of life may have got started at the dawn of life, there was one lineage originated that gave rise to all life on Earth, though exceedingly complex and diversified. This approach is not as straight forward as it once appeared because all life on the planet is divided among three groups (Archaebacteria, Eubacteria, and Eukaryotes), which occupy ranges of several extreme environmental niches, and utilize many different and disparate energy sources. The unity of life derived from a single lineage is a charismatic hypothesis but not yet really scientifically fully proven $[68,72]$. Be that as it may, it is not an optimally scientific tactic in the exploration of the universe, like looking in a mirror, to pursue evidence only for what we already presuppose to know. Chemistry, biochemistry, physics, and thermodynamics need to be examined in concert, since that will improve the chances of detecting life of any sort, without prior prejudice. Fractal forms and symmetries should be compared among various environments. Possibly fractal forms in differentiated environments may be able to discriminate the presence or absence of life. Various principles have been formulated [82, 102]. Statistical analysis and dynamics has become much more complex, including chaos theory and fractals vs. the methods of the last century, such as Gibbs, Maxwell, and Boltzmann theory. The need to utilize new methods looms over future life studies and exploration of exobiology/virology [83-85].

Goldilocks conditions have been located on Enceladus, one of Saturn's moons and the presence of methane has been ascribed as possibly due to microorganisms that are similar to terrestrial deep-sea microorganisms. The terrestrial microorganisms referred to include a methanogenic archaeon, Methanothermococcus okinawensis, that lives in non-aerobic environments in the Pacific Ocean. It is reported that these unique methanogens rely on natural hydrogen production and that they can produce methane. Furthermore, the hydrogen production rate on Enceladus is sufficient to support methanogenic life that is hydrogenotrophic and autotrophic. That an detection of methanol are also discussed in terms of possible life biomarkers [80, 110]. The fundamental question is when a chemical profile is a biosignature.

\subsection{Goldilocks Elements}

The carbon-, nitrogen-, oxygen-, and sulfur-based life positioned on DNA, RNA, proteins, and the rules of terrestrial molecular biology, may not comprise life elsewhere. Detecting organic molecules in exo-environments may relate to other forms of life that we simply have not yet imagined. Even among some terrestrial life forms, for example, silicon enters into metabolism: radiolarians, silici-sponges, and diatoms secrete silica [109]. Life detection elsewhere should include diverse unanticipated scenarios. 


\subsection{Goldilocks Abiogenesis}

That life as we know it arises on Goldilocks habitable zones, relies on the assumption that terrestrial-like environments are the primary harbingers of life [103]. It should be noted that although there is little evidence that such conditions intrinsically produce life (besides the single example of the Earth), though such zones are certainly environments to where terrestrial life could move. An equation was postulated to calculate probabilities for life on Earth. The possibility of material exchange among planets was used to enhance the probability of abiogenesis. However, a Bayesian approach came to the conclusion that despite the existence of life on the Earth, it remains an extremely unlikely event. Moreover, it should be noted that earlier speculations considered that life resembling known terrestrial biochemistry was unlikely $[9,11,68,104,105]$. From this one may infer that the focus on the Goldilocks zone conditions in the search for life is an excessively restrictive approach.

\section{Technology Development}

Since the advent of the Industrial Revolution, science, medicine, and technology intensely developed and progressed. Continued development as it points to extrasolar system investigations requires appropriate additional improvements and advances.

\section{1 von Neumann Universal Constructor Machines}

von Neumann established in the last century, the feasibility of machine replication and error detection and correction. Central is the concept of the "Universal Constructor" of von Neumann's $[111,112]$. Taking this to the next stage of AI, QC, and intelligent robotics, it appears we are embarking on a new age of life made of various metals, semi-conductors, plastics, and other synthetics.

\subsection{AI Robotics in Space Exploration}

Robotics and AI are burgeoning fields in extra-solar system exploration. Such work is proceeding at an accelerated pace. For example, robotic self-supervised learning was accomplished in the laboratory environment to assist independent robot performance in the space exploration environment [113]. This is indicative of progress to fully function and independent robotics that can carry out all functions required ultimately for extra-solar system exploration. 


\subsection{AI and Machine Learning Computation Approaches Related to Medicine and Infectious Diseases (ID)}

AI and machine learning computation approaches related to Medicine and ID were used to develop a more advanced search engine-decision support system of biomedical ontologies than hitherto accomplished. This system utilized infectious disease and antibiotics information for diagnosis classification. This system is for use by ID physicians and care-givers. This is especially useful, when extrapolation of exceedingly complex situations is required, when there is missing data, and when nonetheless, decisions require being made [114].

\subsection{Extra-Solar System Interplanetary Lasers}

Lasers have numerous uses, including communications, optical transponders, precision clocks, pathfinding, orbital dynamics, altimetry, laser propulsion in space, navigation, attitude control, construction, precision alignment, structural control in space, power generation and distribution, resource location including 3D-sensing, materials science, planetary, satellite, asteroid, cometary interior structure and geology, regolith and ice surface mapping, and of course, fulfilling measurement requirements due to Special and General Relativity. Further development will be essential for exo-solar system interplanetary exploration $[115,116]$. Such development is perfect for robotics, AI, and QCs.

Very recently, a closer realization of the use of lasers in communications and lifedetection has been proposed. Stellar gravitational lensing as described in Albert Einstein's theory of General Relativity was used to recommend an inter-solar system means of communication. This is shown to be feasible using an equivalent to a 1 Watt $1 \mathrm{~nm}$ channel laser light in juxtaposition between stars such as the Sun and alpha-Centauri. Possibly, more advanced civilizations may communicate with each other, using even more advanced related technology [117]. This is hardly unreasonable considering how recently we commenced developing our current technologies.

\subsection{Complexity: AI and QC}

Given the numbers of calculations and complexity of interactions that would be required for life to start, let alone the detection of intelligent life, the use of artificial intelligence (AI) as well as Quantum computers (QC) are anticipated to make the calculations and carry out the modeling required to estimate various possibilities, alternatives, and exigencies [87, 88, 118-121]. Scientific development will be greatly accelerated by the development of independent robotics, AI, and QC. Moreover, the sophistication of roving laboratories in planetary and other 
environments will be greatly enhanced with the use of AI and QC improvements. QCs will have to be enhanced so that they operate at several ambient temperatures, utilizing materials that do not require cooling to close to zero degrees Kelvin. These are monumental tasks.

\subsection{A Recent Solar System Event: 1I/2017 U1 (Oumuamua) Transit}

To date, 750,000 asteroids and comets have been detected. However, an unanticipated novel object, 1I/2017 U1, was observed during several nights in October 2017, which twice transited the plane of the solar system, traveling at anomalously high velocity, in an unusual orbit. 1I/2017 U1 is the first object recognized as an extra-solar system visitor. It was suggested that due to various complex calculations, such interstellar visitors have been missed previously. However, it could not be traveled to by direct means. 1I/2017 U1 was initially identified as probably an asteroid, but not a comet. It traversed our solar system with a jolt from the Sun that assisted its hyperbolic exit. It was oblong shaped, with axes that were 200 by 20 meters. Spectroscopic analysis indicated it had a red color, coated with damaged or degraded organic molecules of some kind, and possibly hollow (perhaps with or without trapped internal ice). It was also reported that, unfortunately, we did not have any rockets prepared, which could reach the object and place a probe on it to plot its path as it exited the Solar system beyond visual range. Could laser technology have been used to extend the tracking range [122-124].

Currently, analysis continues for the 4 days of observational data produced from this extra-solar system object. It is most recently considered to have a spotty red color or graded red color scheme. The analysis of this color issue also involves concluding that it has a tumble rate that influences the apparent color analysis. Moreover, 1I/2017 U1 may have been involved in a collision in the distant past, perhaps the cause of its expulsion from the solar system from which it originated [125]. Analysis of the object for signs or signatures of life remain indefinite. Loeb, in 2018, [126] proposed an artificial extraterrestrial interstellar origin for 1I/2017 U1. Of further interest is the proposal of a few stars, originally, calculated to within 2 pc of 1I/2017 $\mathrm{U} 1$ as possible prior sources with ranges of distance and travel times of $0.6 \mathrm{pc}$ at 1 Mya and 1.6 pc at 3.8 Mya [127]. However, it is as yet not anticipated which star, previously to that or originally, may have given rise to 1I/2017 U1. (How old is it? Could it be an intergalactic as well as an interstellar messenger?)

Supporting the notion that interstellar traveling objects have entered our solar system, Siraj and Loeb, in 2019, proposed a $0.45 \mathrm{~m}$ size meteorite (2014-01-08 17:05;34 UTC), with an unbounded hyperbolic orbit and asymptotic extra-solar system velocity of $43.8 \mathrm{~km} / \mathrm{sec}(60 \mathrm{~km} / \mathrm{sec}$ away from the velocity of the Local Standard of Rest [LSR]), is of interstellar origin. In addition, they estimate that there are eight such interstellar objects that have fallen on the Earth [128]. 


\section{Launching Extra-Solar System Exploration: Possible Protocol}

As time goes by, the planning and implementation of extra-solar system missions will be increasingly effective and accelerate with augmented utilization of AI and QC to produce the robotics, universal construction, and analytic and self-sufficient intelligent equipment required. The paradigm suggested for exobiological exploration is to: (1) first produce the robotics (including universal construction), vehicles, communication skills, AI, and QC necessary to analyze, select, and focus on extrasolar planets for detecting intelligence, life, and viruses; (2) This should be done at the feasible distant limits of our solar system; (3) Next, send all these and all necessary probes and landers to various targets and groups of targets (which by then may have different priorities compared to what we know currently); (4) Interstellar space is cold so that with long range communications, QCs that may require cold environments to function, could be stationed at suitable distances from stars. Calculations will be performed at central hubs during extra-solar system investigations; (5) Orbit the selected targets (stars, planets, or other objects); (6) Assess the presence of intelligence $^{6}$ and decide whether to exit or proceed with communications and/or direct exploration; (7) Then, map the targets and analyze them across several wavelengths (X-ray, IR, and visible spectra) and sound, and detect atmospheric chemistry, biochemistry, and particulates (including odors); (8) Send the lander vehicles that will contain the apparatus required to carry out the experiments; (9) All the while, communication links will be maintained; (9) Include detection of migrant planets and planetoids within and outside of solar systems; (10) Along the way, consider the prospect that other such investigations may be taking place. (11) Last and not least, definitely, the appropriate parallel controls for all components of such missions will be continued in suitable places within our solar system, evolving here while the missions evolve distantly during the investigations.

\subsection{Europa Lander Mission Report of 2016}

The development of the Europa Lander Mission report of 2016 demonstrates evolution in approach towards such ends with a wide scope in scientific planning and organization [129, 130]. The 264-page technical report and 734-page planned budget report are very wide-ranging, convey detailed planning, expectations when probes arrive, as well as the sophistication required to get there. These are early steps towards exploration within the solar system; however, the $\$ 19$ billion requested for work 2018-2022 may not be ratified and realistically, the deadline may be shifted towards the late 2020's.

\footnotetext{
${ }^{6}$ Models of extraterrestrial intelligence include both 'natural' and 'artificial' [89]. Both require evaluation prior to interaction with any exobiology or exorobotics.
} 


\section{NIH and NASA Budgets}

What has been the cost for the work done by the US space exploration agency, NASA? According to Wikipedia, the NASA budget from 1958 to 2020 is estimated $\$ 1,188,919,000,000$. In comparison, the NIH budget from 1938 to 2018 is estimated $\$ 737,016,000,000$. The NIH budget expended across 80 years is approximately $62 \%$ of the NASA budget consumed across 62 years. (NIH-supported researchers received 90 Nobel prizes across 78 years, 1939-2017.) [131-133].

\section{What Are the Caveats, if there Is Life Elsewhere?}

NASA scientists, most recently, produced a body of work, related to the possibility of life on Mars.

\subsection{Space Exploration and Potential Contamination of Extraterrestrial Worlds, Planets, and Planetesimals}

Criteria and standards of material/particle contamination have been published for example, related to the European Space Agency (ESA) [134, 135]. However, the implementation, enforcement, and monitoring quality control, followed by peer review publications is not yet implemented globally. Moreover, this entails manufacturing, assembly, and launch stages and there is no systematic program globally in this regard. In addition, since there is a variety of components and procedures internationally, without international monitoring, publication, and quality control, more needs to be done. Clearly, where only materials and particles are monitored, biological (including potential microbial contamination) are not addressed. Although some procedures used could be toxic to microorganisms, it does not mean that living microorganisms are not present as well; furthermore, this cannot be taken to mean that the biological fragments and components of life are absent. Experiments, controls, and simulations are continually required, followed by public reports and expert peer review.

There are many sources of contamination by biological and microbiological organisms, materials, by-products, waste, and detritus. The International Space station, currently and in its prior stages of development, are prime examples. NASA points out that such issues need discussion and practice [136]. 


\subsection{Point-Counter-Point Paradigms: Interplanetary and Inter-Stellar Spread of Life - Svante Arrhenius and Goldilocks}

Sidestepping the all-inclusive question of the probability of more than a single origin of life event within and outside the solar system, is the possibility that microscopic life, once it has originated, could spread throughout any galaxy including our Milky Way. For example, upto $1 \mathrm{~cm}$ size meteorites, originating on a planet such as the Earth, which has microbial life, could be ejected and more than one could reach exoplanets at least 20 light years (ly) distance. Upon terrestrial ejection, such meteorites could reach comets. If the microorganisms remained alive on such ejecta, coupled with comets and other interstellar travelers, then the entire galaxy could be accessible. Along similar lines, the authors state that if life originated, for example, $10^{10}$ (ten billion) years ago, anyplace in the Milky Way, then, by 4.6 billion years ago, life forms could have reached the Earth [137].

There have been heated arguments in contemporary times, relating to the panspermia hypothesis of Svante Arrhenius by many scientist including Wickramasinghe and Hoyle. It should be noted that in ancient times, Anaxagoras (born 510 BCE) first proposed that life came from elsewhere and Arrhenius, in more recent times, proposed this in 1903 [138-141].

Ginsburg and colleagues succinctly summarized ideas and models related to panspermia, with the pervasive presumption of the Goldilocks paradigm. In addition, they assert the possibility of terrestrial ejecta traversing the solar system as well as Milky Way, a central canonical issue for panspermia. Furthermore, they include viruses in their discussions. Suttle and others had previously point out that there are approximately $10^{30}$ viruses, currently, in the Earth's oceans and that viruses have a huge impact globally - that they exhibit the widest genetic diversity on Earth, cause mortality, affect phytoplankton (one of the bases of the ecosystem and food chain on the planet), and drive geochemical cycles. Gonzalez recently pointed out, in a more restricted sense, that although Arrhenius' original canonical panspermia hypothesis in unlikely, what he terms as lithopanspermia of microorganisms that are endolithic and evolve in the same solar system, have increased positive consideration. In addition, terrestrial endolithic life shows unanticipated propensities to survive in caves and other hostile environments [106, 107, 142-146].

However, as inviting as these proposals are in regards to panspermia, for the single known origin of life on the Earth, no evidence except for organic compounds and Goldilocks environments are provided in support. Moreover and most damaging, is the hard experimental evidence that amino acids will not survive the solar wind to a depth of $5 \mathrm{~cm}$ of regolith, let alone the high temperature susceptibilities of biological components and organelles found in any Biochemistry and Biology textbooks [54]. 


\subsection{Reverse Interplanetary and Inter-Stellar Spread of Pathogen Paradigms: Big Bad Wolves Visiting Little Red Riding Hood Habitats}

The dangers of contamination as a direct result of human exploration has been pointed out and discussed for some time - especially in regards to contamination of the Moon and Mars. In addition, it is keenly indicated that samples returned to Earth then inevitably, will contain such contamination and thus distort any subsequent analyses $[147,148]$ Moreover, depending upon the ability of microbial life to replicate, which it has shown even on the Earth to have great capabilities to survive extreme environments, such replication could result in further evolution of such life to then become more toxic and pathogenic. This is an additional stipulation unexplored as yet.

The obverse issue of contamination is whether terrestrial environments could be harmed by toxic and disease-causing reverse contamination - i.e. derived from outside the Earth [149]. These authors conclude that there is very little reason to be concerned and provide a list of reasons why this is of very low probability to occur in the future. The authors thus ignore the lessons taught by all the hundreds of millions of human and animal mortalities and morbidities that have occurred due to microorganisms, including viruses, throughout the last few thousand years of known history on the Earth. (Cf. other chapters in this book as well as references [40, 49]. Most of the epidemics and pandemics were unanticipated, occurred due to lack of understanding of the biology and epidemiology of infectious diseases, as well as lack of understanding of basic molecular biology and biochemistry. This is of course, an ongoing process, and emphasizes the need for greater caution than is the norm.

Before the grave issue of whether there is life on Mars or not is decided, proposals are being made to terraform Mars and for example, increase the Martial surface temperature to bring it more into the Goldilocks zone, [150] i.e. more fit for human habitation. Clearly, this will degrade the problem from being feasible with scientific difficultly, to impossible, and a great opportunity for such study will be lost. That is to say, if it has not already been lost, due to the various objects that have been propelled to Mars. It is important to note that methods for prevention of microbial contamination were in a lower lack of expertise when the first landers were placed on Mars. Even upto contemporary times, as mentioned, although there are many cogent proposals for improved microbial disinfection, there is a lack of organization and standardization that demonstrates lack of clarity and purpose in this regard since the inception of Martian exploration - to prevent terrestrial microbial infection and biological waste on Mars.

\subsection{Deliberate Panspermia - Astrobiology Stem Cells}

There is a concern, in addition to the conundrum as to whether panspermia has occurred among stars and solar systems within galaxies: synthetic panspermia. In addition to the accidental spread of viral and bacterial contamination of Goldilocks 
potential habitats, as previously discussed, there is the possibility of intentional seeding of life with synthetic organisms, synthetic biology. The first such steps have been taken by synthesis of microorganism genomes and their use in the assembly of bacteria.

Synthetic biology has appeared as a promising field for research into the nature of what is alive, health, and financial dynamics. A few key stepping stones are the complete synthesis of several microorganism genomes: poliovirus cDNA by Cello et al., in 2002; phiX174 bacteriophage DNA by Smith et al., 2003; SARS Coronavirus genome by Becker et al. in 2008; and the complete synthesis of the Mycoplasma genitalium genome in 2008. The assembly of a bacterial cell with synthesis of its genome by Venter and colleagues was completed in 2010. Hutchison synthesized a minimal bacterial genome in 2016. Improvements in DNA synthesis techniques assist continued work - difficulties encountered include production of longer than $1 \mathrm{~kb}$ synthons, their assembly into larger structures, the presence of DNA sequences that are toxic to the host organism, sequences that have increased secondary structures, and repetitive sequences [151-153].

As part of studies in evolutionary biology, as synthetic biology advances, organisms may be produced that have evolutionary potential. Adult stem cells and pluripotent cells are used to assist in organ repair in various medical situations. A major hypothesis being researched is whether there are universal stem cells in the adult that exhibit a sufficiently elevated degree of plasticity, circulate throughout the blood stream, able to enter various organs, and then perform their functions [154, 155].

Additionally, it should be noted that possibly, the ability to produce stem cells must have occurred early in evolution prior to the divergence within the eukaryote kingdom, since both plants and animals have stem cells. However, some plants tested can be produced from adult isolated single cells. This is of interest because both plants and animals were exposed to Darwinian evolution [154-156].

In application to panspermia and the origin of life, as genetic and biological engineering progress, a point may be reached whereby cells (Astrobiology stem cells) are produced, which have the capacity for evolution into various unknown and unanticipated life-forms under controlled laboratory conditions, or when released into Astrobiological Goldilocks environmental conditions. Such astrobiology stem cells could be included as von Neumann universal astrobiological constructor living machines [111, 112].

\subsection{Astrobiology Ethics}

Ethical considerations are needed for all the topics covered by this chapter as in any scientific field. This is essential in order to better understand the ethical imperatives of past, current, and future space exploration and its impact on the Earth, Solar system, and galactic Astrobiology. Ethics in science is a well-developed field today and is being applied in the above contexts as well. In addition, the question of sustainability in connection with ethical analysis and understanding are also proposed $[12,13,157-159]$. 


\subsection{Concluding Postscript - Neutrinos and Astrovirology}

Neutrinos are fundamental particles (lepton Fermions) that are distinguished in what are termed, actually, three flavors, electron, muon, and tau neutrinos. They are produced in stars, nuclear reactors, particle accelerators, radioactivity, and in nuclear (bomb) explosions. Once created, through what is termed the Weak force $\left(\mathrm{W}^{ \pm}\right.$and $\mathrm{Z}^{0}$ Bosons), although much lighter, compared to all the other known particles, neutrinos crisscross the universe, rarely interacting with matter. However, they can metamorphose into each other, in transit, called oscillations, and have internal 'clocks', governing them when to do so. Be that as it may, at the Big Bang, apparently though, a special fourth neutrino was produced that is different from the electron, muon, and tau neutrinos, and has been navigating the universe for 14 billion years since the Big Bang [160-168]. All in all, the universe is bathed in several generations and epochs of neutrinos and they are currently being mapped and characterized with a high level of interest. ${ }^{7}$

The fundamental unitary matrix equation describing neutrino oscillations in terms of their flavors, generations, and masses is:

$$
v_{i}=U_{i j} v_{j}
$$

where $\nu_{\mathrm{i}}$ represent the three neutrino flavors, $\mathrm{U}_{\mathrm{ij}}$ is the unitary matrix, and $\nu_{\mathrm{j}}$ is the three putative neutrino masses, which are currently under investigation.

It has been proposed, originally by Pasachoff and colleagues in 1979, that neutrino production by advanced civilizations may someday be detected when our own technologies may advance sufficiently. Strikingly, Stancil et al. were able to demonstrate communication using detectors aimed at terrestrial-produced neutrinos [117, 169-174].

In fine, Ettore Majorana proposed new types of fundamental particles that revolutionized unanticipated concepts of what matter composes the universe, and thereby influenced how we may approach the problems of Astrobiology and Astrovirology in the known universe ${ }^{8}$ [175-178].

\section{Conclusions}

This chapter attempts to encompass and tackle a large problem in Astrovirology and Astrobiology. There is a huge anthropomorphic prejudice that although life is unlikely, the just-right Goldilocks terrestrial conditions mean that the just-right balance of minerals and basic small molecules inevitably result in life as we know it throughout our solar system, galaxy, and the rest of the universe. Moreover, when

\footnotetext{
${ }^{7}$ Trillions of neutrinos traverse each person per second, to provide an idea of their ubiquity.

${ }^{8}$ E.g. are neutrinos Dirac or Majorana fermions?
} 
such conditions on planets such as ours may not be quite right for the origin of life, it is popularly opined that asteroids and comets magically produce life or at the very least, the important, if not crucial components of terrestrial life, so that life then blooms, when their fragments cruise the solar system, stars, and galaxies, and plummet onto appropriately bedecked planets and moons. Be that as it may, it is agreed that life shapes the milieu in which viruses evolve (and vice versa.)

On the one hand, we need to understand how viruses and life originated and evolved on the Earth and indeed great progress has been made. On the other hand, we should not assume it is safe to collide with similar or different forms of life as we and or our machines travel elsewhere. The identification of Goldilocks zone worlds does not self-evidently support the assumption of life, but is indicative, rather, of our possible ability to live on such worlds, hopefully without damaging them. Space agencies and their governments have been well aware of the problems of biological contamination from Earth of extraterrestrial places to be visited and explored. Improved priorities and regulation were set [179, 180].

Although such priorities were promulgated repeatedly, the responsible officials apparently over-all ignored the forewarnings and difficulties pointed out, and contamination has resulted, within a few decades of sloppy and premature exploration, severely annihilating our current and future ability to explore and possibly detect life under the correct pristine scientific conditions that our solar system had provided during some 5 billion years of its prior evolution. Examples of problems already in progress include innumerable artificial satellites orbit the Earth, many have been sent to orbit Mars, the Moon, and other planets, asteroids, and comets, etc. and many probes have crashed or landed on Mars, the Moon, as well as other objects, and several have been propelled out of the solar system. Consequently, these need to be fully catalogued and inventoried to ascertain more fully the extent of the contamination by terrestrial microorganisms and materials that contaminated these probes. This microbial contamination problem is being addressed from a peer review and public perspective and should be corrected before further exacerbations of the problems are continued [181, 182].

Clearly, if life were to exist on Mars, it could be deleterious and pathogenic for any terrestrial life, especially if the Goldilocks approach to life in our solar system were correct. In addition, some Martian and terrestrial organisms could produce new life forms (by synergistic (symbiotic) interactions as well as inter-breeding, depending on their 'biochemistries'), which could then be pathogenic and have unanticipated stark effects. Surely, as one surveys the history of terrestrial catastrophic epidemics and pandemics, most were unanticipated and should be lessons not to under-rate the aggressiveness of many life-forms. Thus, in summary, pathogenicity to any terrestrial life could result from Martian organisms, terrestrial organisms that were conveyed to Mars, and pathogenicity could result in the Martian and terrestrial contexts, including new organisms that interbred. In the obverse, terrestrial life could be inimical to Martian life. This applies to all such exoplanetary explorations.

Finally, to obtain an enhanced perspective of the magnitude and difficulty of the biocontainment problem, please refer to the chapter in this book by Logue et al., which addresses the issue of terrestrial biocontainment at the highest level, BSL-4, for the most pathogenic terrestrial known viruses [29]. 
Acknowledgments Conversations and personal communications are acknowledged: Gilbert Baumslag (Institute for Advanced Study, Princeton, New Jersey); Charles Smith (Princeton University, Princeton, New Jersey); Bishun Khare, Thomas Gold, Frank Drake, and Carl Sagan (Center for Radiophysics and Space Research, Cornell University, Ithaca, NY); Andras Pellionisz (Mountain View, CA); G Rajasekaran, (Institute of Mathematical Sciences, Chennai, India); Andre de Gouvea (Northwestern University, Evanston, IL); Martin Pohl (ESA, Zurich, Switzerland); and Robert Wagoner (Stanford University, Palo Alto, CA).

Conflicts of Interest The author reports no conflicts of interest and also that no robots, AI's, nor QC's were harmed during writing this chapter.

\section{References}

1. Waste and duplication in NASA Programs. https://docs.lib.purdue.edu/cgi/viewcontent. cgi?article $=1096 \&$ context $=$ lib_fsdocs.

2. Space Debris Remediation: an International Relations Approach https://www.researchgate. net/publication/293481473_Space_Debris_Remediation_An_International_Relations_ ApproachSpiegel DS, Turner EL. Bayesian analysis of the astrobiological implications of life's early emergence on Earth. Proc Natl Acad Sci U S A. 2012;109:395-400.

3. NASA Office of Inspector General Annual report, 2018. https://oig.nasa.gov/docs/MC-2018. pdf.

4. Bohlmann UM, Burger MJF. Anthropomorphism in the search for extra-terrestrial intelligence - the limits of cognition? Acta Astronaut. 2018;143:163-8. ISSN 0094-5765. https:// doi.org/10.1016/j.actaastro.2017.11.033.

5. Armstrong S, Sandberg A. Eternity in six hours: intergalactic spreading of intelligent life and sharpening the Fermi paradox. Acta Astronaut. 2013;89:1-13. https://doi.org/10.1016/j. actaastro.2013.04.002. https://flightfromperfection.com.

6. Dyson FJ. Search for artificial stellar sources of infra-red radiation. Science. 1960;131(3414):1667-8.

7. Dyson FJ. The search for extraterrestrial technologies. In: Marshak RE, editor. Perspect mod phys. New York: Wiley; 1966.

8. Newman WI, Sagan C. Galactic civilizations: populations dynamics and interstellar diffusion. Icarus. 1981;46:293-327.

9. Sagan C. Direct contact among galactic civilizations by relativistic interstellar spaceflight. Planet Space Sci. 1963;11:485-98.

10. Kardashev N. On the inevitability and the possible structures of supercivilizations. Search for Extraterrestrial Life. Proc. Symp. Boston, Massachusetts. June, 1984. Dordrecht Publ. Co.; 1985. p. 497-504.

11. Sagan C, Dyson FJ, Morrison D. Cosmic connection: an extraterrestrial retrospective. 1973. ISBN 978-0-521-78303-3.

12. Cockell CS. Astrobiology and the ethics of new science. Interdisc Sci Rev. 2001;26 https:// doi.org/10.1179/0308018012772533.

13. Cockell CS. Using exoplanets to test the universality of biology. Nat Astronomy. 2018;2:758-9.

14. Wandel A. On the abundance of extraterrestrial life after the Kepler mission. Int J Astrobiol. 2015;14(3):511-6. https://doi.org/10.1017/S1473550414000767.

15. Thucydides. The History of the Peloponnesian War. 431-404 B.C. (Translated by R. Crawley). The Internet Classics Archive. http://classics.mit.edu//Thucydides/pelopwar.html; http://classics.mit.edu/Thucydides/pelopwar.mb.txt.

16. Marshall DC. Periodical cicada (Homoptera: Cicadidae) life-cycle variations, the historical emergence record, and the geographic stability of brood distributions. Ann Entomol Soc Am. 2001;94:386-99. 
17. Grant PR. The priming of periodical cicada life cycles. Trends Ecol Evol. 2005;20:169-74.

18. Mayfly. http://www.wildtrout.org/sites/default/files/projects/teachers_introduction_to_mayfly_in_the_classroom.pdf.

19. Girimonte D, Izzo D. AI for space applications. 2007. doi:https://doi. org/10.1007/978-1-84628-943-9_12.

20. Shabbir J, Anwer T. AI and its role in near future. April 1, 2018. arXiv:1804.01396v1 [cs.AI].

21. Javaux EJ, Lepot K. The Paleoproterozoic fossil record: implications for the evolution of the biosphere during Earth's middle-age. Earth Sci Rev. 2017; https://doi.org/10.1016/j. earscirev.2017.10.001.

22. Schopf JW. The fossil record of cyanobacteria. In: Whitton B, editor. Ecology of cyanobacteria II. Dordrecht: Springer; 2012. https://doi.org/10.1007/978-94-007-3855-3_2.

23. Grady MM, Wright IP, Pillinger CT. Microfossils from Mars: a question of faith. Astron Geophys. 1997;38:26-9. https://academic.oup.com/astrogeo/article-abstract/38/1/26/224846.

24. Meteorite society 2019. http://meteoritical.org.

25. Christoffersen R, Lindsay JF, Noble SK, Meador MA, Kosmo JJ, Lawrence JA, Brostoff L, Young A, McCue T. Lunar dust effects on spacesuit systems: insights from the apollo spacesuits. NASA/TP-2008-000000. https://ntrs.nasa.gov/archive/nasa/casi.ntrs.nasa. gov/20090015239.pdf.

26. Gaier JR. The effects of lunar dust on EVA systems during the apollo missions. NASA/ TM-2005- 213610. https://www.hq.nasa.gov/alsj/TM-2005-213610.pdf.

27. O'Brien BJ, Gaier JR. Indicative basic issues about lunar dust in the lunar environment. A white paper for the National Academies Planetary Sciences Decadal Survey. 2009. https:// www3.nd.edu/ cneal/Lunar-L/LunarDustBasics.pdf.

28. Fernandez F, Minagar A, Alekseeva N, Shapshak P. Neuropsychiatric aspects of prion disease. In: Sadock BJ, Sadock VA, Ruiz P, editors. Comprehensive textbook of psychiatry. New York: Kluwer and Lippincott Publ; 2017. p. 601-18.

29. Logue J, Solomon J, Niemeyer BF, Benam KH, Lin AE, Bjornson Z, Jiang S, McIlwain DR, Nolan GP, Palacios G, Kuhn JH. Innovative technologies for advancement of WHO risk group 4 pathogens research. New York: Springer; 2019. Chapter in this volume.

30. Chippaux J-P. Outbreaks of Ebola virus disease in Africa: the beginning of a tragic saga. J Venom Anim Toxins Incl Trop Dis. 2014;20:1-14.

31. Ladner JT, Wiley MR, Mate S, Dudas G, Prieto K, Lovett S, Nagle ER, Beitzel B, Gilbert ML, Fakoli L, Diclaro JW II, Schoepp RJ, Fair J, Kuhn JH, Hensley LE, Park DJ, Sabeti PC, Rambaut A, Sanchez-Lockhart M, Bolay FK, Kugelman JR, Palacios G. Evolution and spread of Ebola virus in Liberia, 2014-2015. Cell Host Microbe. 2015;18:659-69.

32. Kuhn JH. In: Kuhn JH, Calisher CH, editors. Filoviruses. A compendium of 40 years of epidemiological, clinical, and laboratory studies. New York: Springer; 2015.

33. BSL-4.: https://en.wikipedia.org/wiki/Biosafety_level.

34. Bradfute SB, Jahrling PB, Kuhn JH. Chapter 20. Ebola virus disease. Global virology I identifying ad investigating viral diseases. New York: Springer; 2015. p. 543-59.

35. Jahrling PB, Keith L, St. Claire M, Johnson RF, Bollinger L, Matthew G, Lackemeyer MG, Lisa E, Hensley LE, Jason Kindrachuk J, Kuhn JH. The NIAID Integrated Research Facility at Frederick, Maryland: a unique international resource to facilitate medical countermeasure development for BSL-4 pathogens. Pathog Dis. 2014;71:213-8.

36. Janosko K, Holbrook MR, Adams R, Barr J, Bollinger L, Newton JT, Ntiforo C, Coe L, Wada J, Pusl D, Jahrling PB, Kuhn JH, Lackemeyer MG. Safety precautions and operating procedures in an (A)BSL-4 laboratory: 1. Biosafety level 4, suit laboratory, suite entry, and exit procedures. J Vis Exp. 2016;116:e52317. https://doi.org/10.3791/52317.

37. Dyer O. Congo's Ebola epidemic is now at its worst ever and still spreading. BMJ. 2019;362:1433-41. https://doi.org/10.1136/bmj.1433.

38. DRC Health Ministry. 2019. https://us13.campaign-archive.com/?u=89e5755d2cca4840b1af 93176\&id $=21512 \mathrm{e} 200 \mathrm{~b}$.

39. Christaki E. New technologies in predicting, preventing and controlling emerging infectious diseases. Virulence. 2015;6:558-65. 
40. Shapshak P, Sinnott JT, Somboonwit C, Kuhn JH. Global virology I - identifying and investigating viral diseases. New York: Springer; 2015b.

41. Parrish CR, Holmes EC, Morens DM, Park EC, Burke DS, Calisher CH, Laughlin CA, Saif LJ, Dazak P. Cross-species virus transmission and the emergence of new epidemic diseases. Microbiol Mol Biol Rev. 2008;72:457-70.

42. Geoghegan JL, Duchenne S, Holmes EC. Comparative analysis estimates of the relative frequencies of co-divergence and cross-species transmission within viral families. PLoS Pathol. 2017;13:1-17. https://doi.org/10.1371/journal.ppat.1006215.

43. NASA meteor report. https://www.nasa.gov/sites/default/files/files/Meteors_Meteorites_ Lithograph.pdf.

44. Min K, Reiners PW. High-temperature Mars-to-Earth transfer of meteorite ALH84001. Earth Planet Sci Lett. 2007;260:72-85.

45. Tayro EAM, Scott ERD, Sharma SK, Misra AK. The pressures and temperatures of meteorite impact: evidence from micro-Raman mapping of mineral phases in the strongly shocked Taiban ordinary chondrite. Am Mineral. 2013;98:859-69. https://doi.org/10.2138/ am.2013.4300.

46. Acosta-Maeda TE, Scott ERD, Sharma SK, Misra AK. The pressures and temperatures of meteorite impact: evidence from micro-Raman mapping of mineral phases in the strongly shocked Taiban ordinary chondrite. Am Mineral. 2013;98:859-69.

47. Jenniskens P, Laux CO, Wilson MA, Schaller EL. The mass and speed dependence of meteor air plasma temperatures. Astrobiology. 2004;4:1-14.

48. Chyba C, Sagan C. Endogenous production, exogenous delivery and impact-shock synthesis of organic molecules: an inventory for the origins of life. Nature. 1992;355:125-32. https:// doi.org/10.1038/355125a0.

49. Kant I. Allgemeine Naturgeschichte und Theorie des Himmels. Konigsberg, Leipzig: Petersen Publications; 1755.

50. Callahan MP, Smith KE, HJ Cleaves II, Ruzick J, Stern JC, Glavin DP, House CH, Dworkin JP. Carbonaceous meteorites contain a wide range of extraterrestrial nucleobases. Proc Natl Acad Sci U S A. 2011;108:13995-8. https://doi.org/10.1073/pnas.1106493108.

51. Schmitt-Kopplin P, et al. High molecular diversity of extraterrestrial organic matter in Murchison meteorite revealed 40 years after its fall. Proc Natl Acad Sci U S A. 2010;107:2763-8.

52. Sephton MA. Organic compounds in carbonaceous meteorites. Nat Prod Rep. 2002;19:292-311.

53. Engel MH, Macko SA. Isotopic evidence for extraterrestrial non-racemic amino acids in the Murchison meteorite. Nature. 1997;389:265-8.

54. Sagan C, Bilson E, Raulin F, Shapshak P. Amino acid destruction under simulated lunar conditions. Center for Radiophysics and Space Research, Cornell University, Ithaca. Report number 488 1971. https://ntrs.nasa.gov/archive/nasa/casi.ntrs.nasa.gov/19790024970.pdf.

55. Loeb A. The habitable epoch of the early universe. 2014. arXiv:12.0613v3 [astro-ph.CO].

56. Gibson $\mathrm{CH}$. The biological big bang: the first oceans of primordial planets at 2-8 million years explain Hoyle/ Wickramasinghe cometary panspermia. Proc SPIE 8152-37. 2011. p. 1-19.

57. Sagan C. Ultraviolet selection pressure on the earliest organisms. Ithaca. Report number 445: Center for Radiophysics and Space Research, Cornell University; 1971.

58. Sagan C, Shapshak P. On ultraviolet light and the origin of ribosomes. Ithaca). Report number 446: Center for Radiophysics and Space Research, Cornell University; 1971.

59. Fox GE. Origin and evolution of the ribosome. Cold Spring Harb Perspect Biol. 2010;2:a003483. https://doi.org/10.1101/cshperspect.a003483.

60. Benner SA, Kim HJ, Yang Z. Setting the stage: the history, chemistry, and geobiology behind RNA. Cold Spring Harb Perspect Biol. 2012;4:a003541. https://doi.org/10.1101/cshperspect. a003541.

61. Robertson MP, Joyce GF. The origins of the RNA world. Cold Spring Harb Perspect Biol. 2012;4:a003608. https://doi.org/10.1101/cshperspect.a003608.

62. Blaustein R. Advances in astrobiology. Bioscience. 2015;65:460-5. https://doi.org/10.1093/ biosci/bivsys. 
63. Gray MW. Lynn Margulis and the endosymbiont hypothesis: 50 years later. Mol Biol Cell. 2017;28:1285-7. https://doi.org/10.1091/mbc.E16-07-0509. PMID: 28495966. PMCID: PMC5426843.

64. Lopez-Garcia P, Emeb L, Moreiraa D. Symbiosis in eukaryotic evolution. J Theor Biol. 2017; https://doi.org/10.1016/j.jtbi.2017.02.031.

65. Mereschkowsky C. Uber natur und usprung der chromatophoren im pflanzenreiche. Biol Cent. 1905;25:593-604.

66. Mereschkowsky K. Theorie der zwei Plasmaarten als Grundlage der Symbiogenesis, einer neuen Lehre von der Ent-stehung der Organismen. Biol Cent. 1910;30:353-67.

67. Sagan L. On the origin of mitosing cells. J Theor Biol. 1967;14:255-74.

68. Sagan C. Definitions of life. This chapter originally appeared as the first section in the entry for "Life" in Encyclopedia Britannica, pp. 1083-1083A, Chicago: Encyclopedia Britannica Incorporated, 1970. http://dnapunctuation.org/ poptsova/course2012/Sagan\%20 Definitions\%20of\%20life.pdf.

69. Schrodinger E. What is life? Mind and matter. Cambridge: Cambridge University Press; 1967. (First published in 1944).

70. Rabinowitch E, Govindjee. Photosynthesis. New York: Wiley; 1969. ISBN 471704245.

71. Haaker H. Biochemistry and physiology of nitrogen fixation. BioEssays. 1988;9:112. https:// doi.org/10.1002/bies.950090403.

72. Leningher A. Principles of biochemistry. 7th ed. Accessed 4 Sept 2018. http://www.esalq.usp. br/lepse/imgs/conteudo_thumb/mini/Principles-of-Biochemistry-by-ALbert-Leningher.pdf.

73. Wilson EK, Walker J. Principles and techniques of biochemistry and molecular biology. In: Wilson K, Walker J, editors. Cambridge, UK: Cambridge University Press; 2010. http://www. kau.edu.sa/Files/0017514/Subjects/principals\%20and\%20techiniques\%20of\%20biochemistry\%20and\%20molecular\%20biology\%207th\%20ed\%20wilson\%20walker.pdf.

74. Vasudevan DM, Sreekumari S, Vaidyanathan K. Textbook of biochemistry for medical students. New Delhi: Jaypee Brothers Medical Publ. (P) Ltd; 2011. https://ia802205.us.archive. org/1/items/pdfy-5vClyqSbVzIGpuT2/DM\%20Vasudevan\%20-\%20Textbook\%20of\%20 Biochemistry\%20For\%20Medical\%20Students\%2C\%206th\%20Edition.pdf.

75. Prigogine I. Thermodynamics of irreversible processes. New York: Wiley; 1967.

76. Klotz IM, Rosenberg RM. Chemical thermodynamics: basic concepts and methods. Hoboken: Wiley; 2008.

77. Klotz IM. Energetics in biochemical reactions. New York: Academic Press Inc; 1957.

78. Tolman RC. Relativity, thermodynamics, and cosmology. Mineola: Dover Publications; 1987.

79. de Waele ATAM. The first, second, and third laws of thermodynamics (ThLaws05.tex). 2009. http://cryocourse2011.grenoble.cnrs.fr/IMG/file/Lectures/2011-deWaele-ThLaws05.pdf.

80. Taubner RS, Pappenreiter P, Zwicker J, Smrzka D, Pruckner C, Kolar P, Bernacchi S, Seifert AH, Krajete A, Bach W, Peckmann J, Paulik C, Firneis MG, Schleper C, Rittmann SKMR. Biological methane production under putative Enceladus-like conditions. Nat Commun. 2018;9:748. https://doi.org/10.1038/s41467-018-02876-y.

81. Masuda T, Dobson GP, Veech RL. The Gibbs-Donnan near-equilibrium system of heart. J Biol Chem. 1990;265:20321-34.

82. Tel T. Fractals, multifractals, and thermodynamics. Z. Naturforsch. 1988;43a:1154-74.

83. Denisov S. Fractal binary sequences: tsallis thermodynamics and Zipf's law. Electromagnet Stud. 1998;I:64-8.

84. Gaspard P. Chaos, fractals, and thermodynamics. Bull Cl Sci Acad R Belg. 2000;6e-XI:9-48.

85. Deppman D. Thermodynamics with fractal structure, Tsallis statistics, and hadrons. 2016. arXiv:1601.02400v1 [hep-ph] 11 Jan 2016.

86. Weberszpil J, Chen W. Generalized maxwell relations in thermodynamics with metric derivatives. Entropy. 2017;19:407-19. https://doi.org/10.3390/e19080407.

87. Shapshak P, Somboonwit C, Sinnott JT. Artificial Intelligence and Virology - quo vadis. Bioinformation. 2017a;13(12):410-1.

88. Shapshak P. Artificial intelligence and brain. Bioinformation. 2018;14(1):038-41. 
89. Zak M. A model of emerging intelligence in Universe. Int J Astrobiol. 2019;18(3):251-8. https://doi.org/10.1017/S1473550417000489.

90. Balaji S, Akash R, Krittika N, Shapshak P. Sequence accuracy in primary databases: a case study on HIV-1B. In: Shapshak P, Levine AJ, Somboonwit C, Foley BT, Singer E, Chiappelli F, Sinnott JT, editors. Global virology II. HIV and NeuroAIDS. New York: Springer; 2017.

91. Sneha P, Balaji S, Shapshak P. Amyloidogenic pattern prediction of HIV-1 proteins. In: Shapshak P, et al., editors. Chapter 33 in Global virology II - HIV and NeuroAIDS. New York: Springer; 2017. p. 823-95. https://doi.org/10.1007/978-1-4939-7290-6_33.

92. Geschwind MD. Prion diseases. Continuum (Minneap Minn). 2015;21(6 Neuroinfectious disease):1612-38. https://doi.org/10.1212/CON.0000000000000251.

93. Furr A, Young AJ, Richt J. The immune system in the pathogenesis and prevention of prion diseases. J Bioterr Biodef. 2012;S1:012. https://doi.org/10.4172/2157-2526.S1-012.

94. Gianluigi F, Balducci C. Beta-amyloid oligomers and prion protein - fatal attraction? Prion. 2011;5:10-5.

95. Boland CR. Non-coding RNA: it's not junk. Dig Dis Sci. 2017;62:1107-9. https://doi. org/10.1007/s10620-017-4506-1.

96. Antonarakis SE. Human genome sequence variation. In: Speicher M, Antonarakis SE, Motulsky AG, editors. Human genetics: problems and approaches. New York: Springer; 2009. p. 981.

97. NIH Roadmap and personalized medicine. https://commonfund.nih.gov/sites/default/ files/ADecadeofDiscoveryNIHRoadmapCF.pdf https://newsinhealth.nih.gov/2013/12/ personalized-medicine.

98. Shapshak P, Chiappelli F, Commins D, Singer E, Levine AJ, Somboonwit C, Minagar A, Pellionisz A. Molecular epigenetics, chromatin, and NeuroAIDS/HIV: translational implications. Bioinformation. 2008;3:53-7.

99. Shapshak P, Levine AJ, Somboonwit C, Foley BT, Singer E, Chiappelli F, Sinnott JT. Global virology II. HIV and NeuroAIDS. New York: Springer; 2017b.

100. Shapshak P. Challenges in health research funding: an opinion. Bioinformation. 2015c;11(2):55-6.

101. Steward CA, Parker APJ, Minassian BA, Sisodiya SM, Frankish A, Harrow J. Genome annotation for clinical genomic diagnostics: strengths and weaknesses. Genome Med. 2017;9:49. https://doi.org/10.1186/s13073-017-0441-1.

102. Pellionisz AJ. The principle of recursive genome function. Cerebellum. 2008;7:348-59. https://doi.org/10.1007/s12311-008-0035-y.

103. Forget F. On the probability of habitable planets. Int J Astrobiol. 2013; https://doi.org/10.1017/ S1473550413000128.

104. Spiegel DS, Turner EL. Bayesian analysis of the astrobiological implications of life's early emergence on Earth. Proc Natl Acad Sci U S A. 2012;109:395-400.

105. Scharf C, Cronin L. Quantifying the origins of life on a planetary scale. Proc Natl Acad Sci U S A. 2016; https://doi.org/10.1073/pnas.1523233113.

106. Gonzalez G. Review: setting the stage for habitable planets. Life. 2014;4:1-27. https://doi. org/10.3390/life40x000x.

107. Gonzalez Oreja JA. Quo vadis, panspermia? Del origen de la vida en la Tierra a una ecologia interplanetaria. eVOLUCION. 2016;11(1):71-88.

108. Woolfson M. Planet formation and the evolution of the Solar System. 2017. https://arxiv.org/ pdf/1709.07294.

109. Wooldridge SA. Mass extinctions past and present: a unifying hypothesis. Biogeosci Discuss. 2008;5:2401-23.

110. Drabek-Maunder E, Greaves J, Fraser H, Clements D, Alconcel L. Ground-based detection of a cloud of methanol from Enceladus: when is a biomarker not a biomarker? Int J Astrobiol. 2017:1-8. https://doi.org/10.1017/S1473550417000428.

111. von Neumann J. Theory of self-replicating automata. In: Burks AW, editor. Urbana: University of Illinois Press; 1966. 
112. Pesavento U. An implementation of von Neumann's self-reproducing machine. Artif Life. 1995;2:337-54. (Princeton University and Massachusetts Institute of Technology).

113. van Hecke K, de Croon GCHE, Hennes D, Setterfield TP, Saenz-Otero A. Self-supervised learning as an enabling technology for future space exploration robots: ISS experiments on monocular distance learning. Acta Astronaut. 2017;140:1-9. https://doi.org/10.1016/j. actaastro.2017.07.038.

114. Shen T, Yuan K, Chen D, Colloc J, Yang M, Li Y, Lei K. An ontology-driven clinical decision support system (IDDAP) for infectious disease diagnosis and antibiotic prescription. Artificial. Intelligence in Medicine. 2018. https://www.sciencedirect.com/science/article/pii/ S0933365717302348.

115. Dirkx D, Noomen R, Visser PNAM, Gurvits L, Vermeersen LLA. Space-time dynamics estimation from space mission tracking data. Astron Astrophys. 2015;. https://arxiv.org/ pdf/1512.06685.pdf

116. Turyshev SG, Williams JG, Shao M, Anderson JD. Laser ranging to the Moon, Mars, and beyond. The 2004 NASA/JPL Workshop on Physics for Planetary Exploration. April 20-22, 2004, Solvang, CA. https://arxiv.org/abs/gr-qc/0411082v1.

117. Hippke M. Interstellar communication. II. Application to the solar gravitational lens. Acta Astronaut. 2018;142:64-74.

118. Feynman R. New Directions in Physics: the Los Alamos 40th anniversary volume. In: Metropolis N, Kerr DM, Rota G-C, editors. Orlando: Academic Press, Inc.; 1987.

119. Feynman R. Quantum mechanical computers. Optic News. 1985;11:11-20. https://doi. org/10.1364/ON.11.2.000011.

120. Gudder SP. Stochastic methods in quantum mechanics. Mineola: Dover Publications, Inc; 1979.

121. Shapshak P. Challenges in Health Research Funding: an opinion. Bioinformation. 2015a;11(2):55-6. PMCID: PMC4369678.

122. Meech KJ, Weryk R, Micheli M, Kleyna JT, Hainaut OR, Jedicke R, Wainscoat RJ, Chambers KC, Keane JV, Petric A, Denneau L, Magnier E, Berger T, Huber ME, Flewelling H, Waters C, Schunova-Lilly E, Chastel S. A brief visit from a red and extremely elongated interstellar asteroid. Nature. 2017;552:378-81. https://doi.org/10.1038/nature25020.

123. Schneider J. Is 1I/2017 U1 really of interstellar origin. 2017. arXiv:1711.05735v1.

124. Fitzsimmons A, Snodgrass C, Rozitis B, Yang B, Hyland M, Seccull T, Bannister MT, Fraser WC, Jedicke R, Lacerda P. Spectroscopy and thermal modelling of the first interstellar object 1I/2017 U1 'Oumuamua. ArXiv:1712.06552v1.

125. Fraser WC, Pravec P, Fitzsimmons A, Lacerda P, Bannister MT, Snodgrass C, Smolic I. The tumbling rotational state of 11/Oumuamua. Nat Astronomy. 2018; https://doi.org/10.1038/ s41550-018-0398-z.

126. Loeb A. Six strange facts about our first interstellar guest, 'Oumuamua'. 2018. arXiv:1811.08832.

127. Bailer-Jones CAL, Farnocchia D, Meech KJ, Brasser R, Micheli M, Chakhrabarti S, Buie MW, Hainaut OR. Plausible home stars of the interstellar object 'Oumuamua' found in Gaia DR2. 2018. arXiv: 1809.09009v1.

128. Siraj A, Loeb A. Identifying interstellar objects trapped in the solar system through their orbital parameters. 2019. arXiv:1811.09632v5 [astro-ph.EP] 4 Feb 2019.

129. Europa Lander Mission, Lander Study - 2016 report - JPL D-97667. NASA. Hand KP and the project engineering team. 2017.

130. Europa mission. https://www.space.com/36993-nasa-europa-mission-launch-date-2018-budget.html.

131. NASA budget. https://en.m.wikipedia.org/wiki/Budget_of_NASA.

132. NIH Budget. https://en.wikipedia.org/wiki/National_Institutes_of_Health.

133. NIH Nobel Laureates. https://www.nih.gov/about-nih/what-we-do/nih-almanac/nobel-laureates.

134. Faye D, Rampini R. Contamination control policy: last publication standards in standardizations. http://esmat.esa.int/Materials_News/ISME09/pdf/6-Contamination/S8\%20-\%20Faye.pdf. 
135. ECSS Secretariat, ESA-ESTEC, Requirements \& Standards Division, Noordwijk, The Netherlands. Space product assurance Cleanliness and contamination control. 2008. https:// escies.org/download/webDocumentFile?id=62823.

136. NASA. International Space Station, 2009. https://www.nasa.gov/pdf/393789main_iss_utilization_brochure.pdf.

137. Hara T, Takagi K, Kajiura D. Transfer of life-bearing meteorites from earth to other planets. J Astrobiol Space Sci Rev. 2019;1:299-310.

138. Arrhenius S. Die Verbreitung des Lebens im Weltenraum. Die Umschau, Frankfurt a.M. 1903;7:481-6.

139. O'Leary MR. Anaxagoras and the origin of Panspermia theory. In iUniverse. ISBN 978-0595-49596-2. OCLC 757322661. 2008.

140. Wickramasinghe C. The astrobiological case for our cosmic ancestry. Int J Astrobiol. 2010;9:119-25.

141. Wickramasinghe MK, Wickramasinghe C. Interstellar transfer of planetary microbiota. Mon Not R Astron Soc. 2004;348:52-7. https://doi.org/10.1111/j.1365-2966.2004.07355.x.

142. Boston PJ, Spilde MN, Northup DE, Melim LA, Soroka DA, Kleina LG, Lavoie KH, Hose LD, Mallory LM, Dahm CN, Crossey LJ, Scheble RT. Cave biosignature suites: microbes, minerals and Mars. Astrobiology. 2001;1:25-55.

143. Melim LA, Liescheidt R, Northup DE, Spilde MN, Boston PJ, Queen JM. A biosignature suite from cave pool precipitates, Cottonwood cave, New Mexico. Astrobiology. 2009;9:907-17.

144. Ginsburg I, Lingam M, Loeb A. Galactic panspermia. 2018. arXiv:1810.04307v2 [astroph.EP].

145. Suttle C. Viruses in the sea. Nature. 2005;437:356-9.

146. Weinberg KD. Viruses in marine ecosystems: from open waters to coral reefs. Adv Virus Res. 2018;101:1-38. https://doi.org/10.1016/bs.aivir.2018.02.001.

147. Glavin DP, Dworkin JP, Lupisella M, Kminek G, Rumme JD. Biological contamination studies of lunar landing sites: implications for future planetary protection and life detection on the Moon and Mars. Int J Astrobiol. 2005:265-71. https://doi.org/10.1017/S1473550404001958. https://ntrs.nasa.gov/archive/nasa/casi.ntrs.nasa.gov/20040084463.pdf.

148. Glavin DP, Dworkin JP, Lupisella M, Kminek G, and Rumme JD. In situ biological contamination studies of the moon: implications for future planetary protection and life detection missions. 2010. https://ntrs.nasa.gov/archive/nasa/casi.ntrs.nasa.gov/20100036597.pdf.

149. Netea MG, van de Veerdonk FL, Strous M, van der Meer JWM. Infection risk of a human mission to Mars. J Astrobiol Space Sci Rev. 2019;1:144-55.

150. Ridder NN, Maan DC, Summerer L. Terraforming Mars: generating greenhouse gases to increase martian surface temperatures. J Astrobiol Space Sci Rev. 2019;1:338-52.

151. Hughes RA, Ellington AD. Synthetic DNA synthesis and assembly: putting the synthetic in synthetic biology. Cold Spring Harb Perspect Biol. 2017;9:a023812.

152. Hutchison CA 3rd, Chuang RY, Noskov VN, Assad-Garcia N, Deerinck TJ, Ellisman MH, Gill J, Kannan K, Karas BJ, Ma L. Design and synthesis of a minimal bacterial genome. Science. 2016;351:aad6253.

153. Zhang LY, Chang SH, Wang J. Synthetic biology: from the first synthetic cell to see its current situation and future development. Chin Sci Bull. 2011;56:229-37. https://doi.org/10.1007/ s11434-010-4304-z.

154. Chakraborty C, Agoramoorthy G. Stem cells in the light of evolution. Review article. Indian J Med Res. 2012;135:813-9.

155. The stem cell book-NIH stem cell information. https://stemcells.nih.gov Cited 4-15-2019.

156. Hartenstein V. Stem cells in the context of evolution and development. Dev Genes Evol. 2013;223 https://doi.org/10.1007/s00427-012-0430-8.

157. Arnould J. Astrobiology, sustainability and ethical perspectives. Sustainability. 2009;1:1323-30. https://doi.org/10.3390/su1041323.

158. Losch A. The need of an ethics of planetary sustainability. Int J Astrobiol. 2017; https://doi. org/10.1017/S14735550417000490. 
159. Rodriguez HE, Lakshmi S, Somboonwit C, Oxner A, Guerra L, Addisu A, Gutierrez L, Sinnott JT, Nilofer C, Kangueane P, Shapshak P. Gene therapy blueprints for NeuroAIDS. In: Shapshak P, Levine AJ, Foley BT, Somboonwit C, Singer E, Chiappelli F, Sinnott JT, editors. Global virology II - HIV and NeuroAIDS. New York: Springer; 2017. p. 953-93.

160. de Gouveia A. Neutrino Mass Models. Ann Rev Nucl Part Sci. 2016;66:197-215.

161. de Gouveia A. Neutrino Anomalies \& CEvNS. PIRE Workshop. COFI February 6-7, 2017a.

162. de Gouveia A. Neutrino physics. Evanston). Lectures at Institute for Advanced Study (Princeton, NJ): Northwestern University; 2017b.

163. de Gouveia A. https://cpb-us-e1.wpmucdn.com/sites.northwestern.edu/dist/8/307/files/2017/08/ Andre-de-Gouvea-PIRE_PR_2017-16t79ju.pdf; 2017c.

164. Hannestad S. Aspects of neutrino physics in the early universe. PhD Thesis. Institute of Physics and Astronomy, University of Aarhus, Copenhagen, Denmark. 1997. http://phys. au.dk/fileadmin/site_files/publikationer/phd/Steen_Hannestad.pdf.

165. Freedman WL. The Hubble constant and the expansion age of the Universe. Phys Rep. 2000;334:13-31.

166. Rajasekaran G. Phenomenology of neutrino oscillations. Pramana. 2000;55:19-5.

167. Indumathi D, Murthy MVN, Rajasekaran G. Perspectives in Neutrino Physics. Proc India Natl Sci Acad-Part A. 2004;70:1-15.

168. INO web-site: http://www.imsc.res.in/ ino.

169. Pasachoff JM, Kutner ML. Neutrinos for interstellar communication. Cosmic Search. 1979:2-21.

170. Hippke M. Interstellar communication. IV. Benchmarking information carriers. Acta Astronaut. 2018b;151:53-62.

171. Learned JG, Pakvasa S, Zee A. Galactic neutrino communication. Phys Lett B. 2009;671:15-9.

172. Stancil DD, Brooks W, Alania M, 110 additional authors. Demonstration of communication using neutrinos. Mod Phys Lett A. 2012:1-10.

173. Silagadze ZK. SETI and muon collider. 2008. arXiv:0803.0409v1.

174. Cavanna F, Costantinia ML, Palamarab O, Vissani F. Neutrinos as astrophysical probes. 2003. arXiv:astro-ph/0311256v1 11 Nov 2003.

175. Recami E. Ettore Majorana: the scientist and the man. Int J Mod Phys D. 2014;16:1-23. https://www.researchgate.net/publication/269762476_ETTORE_MAJORANA_HIS_ WORK_AND_HIS_LIFE_in_English_-_and_with_some_up-dated_Bibliography.

176. Esposito S. Majorana solution of the Thomas-Fermi equation. Am J Phys. 2002a;70:852-63.

177. Esposito S. Majorana transformation for differential equations. Int $\mathrm{J}$ Theor Phys. 2002b;41:2417-31.

178. Di Grezia E, Esposito S. Fermi, Majorana and the statistical model of atoms. Found Phys. 2004;34:1431-52.

179. Hall LB, Miles JR, Bruch CW, Tarver P. The objectives and technology of spacecraft sterilization. Washington, DC: NASA History Division, NASA Headquarters; 1995. 542pp.

180. Meltzer M. When biospheres collide. A history of NASA's planetary protection program. 2011. NASA SP-2011-4234.

181. Rhawn J. Sterilization failure and fungal contamination of Mars and NASA's Mars rovers. J Cosmol. 2018;30:51-97. https://www.researchgate.net/publication/322702459.

182. Faire AG, Parro V, Schulze-Makuch D, Whyte L. Searching for life on Mars before it is too late. Astrobiology. 2018;17:962-70. https://doi.org/10.1089/ast.2017.1703. 